\title{
Relationship between self-care and social and clinical conditions of patients with heart failure
}

\author{
Relação entre autocuidado e condições sociais e clínicas de pacientes com insuficiência \\ cardíaca
}

Mailson Marques de Sousa ${ }^{1}$, Taciana da Costa Farias Almeida ${ }^{1}$, Bernadete de Lourdes André Gouveia ${ }^{1}$, Marta Ferreira de Carvalho ${ }^{1}$, Fabiana Medeiros de Brito ${ }^{1}$, Simone Helena dos Santos Oliveira ${ }^{1}$

Objective: to identify the relationship between self-care measures and the social and clinical conditions of patients with heart failure. Methods: a cross-sectional study with 100 patients with heart failure, in outpatient follow-up. To assess self-care, the European Heart Failure Self-care Behavior Scale was used. Descriptive and inferential statistics were applied. Results: the self-care score presented an average of $35.17 \pm 7.87$, with a variation of 15 to 54 points. A lower average was found in the self-care score for female patients, with a significant difference $(\mathrm{p}<0.009)$. The recognition of the presence of lower limb edema, the daily monitoring of body weight and the regular practice of physical activity were presented as self-care measures with greater disagreement among the investigated participants. Conclusion: a better relationship was found between the self-care measures and the female sex.

Descriptors: Heart Failure; Self Care; Nursing.

Objetivo: identificar a relação entre as medidas de autocuidado e as condições sociais e clínicas de pacientes com insuficiência cardíaca. Métodos: estudo transversal com 100 pacientes com insuficiência cardíaca, em seguimento ambulatorial. Para avaliar o autocuidado, utilizou-se a European Heart Failure Self-care Behavior Scale. Aplicou-se estatística descritiva e inferencial. Resultados: o escore de autocuidado apresentou média de $35,17 \pm 7,87$, com variação de 15 a 54 pontos. Constatou-se menor média no escore de autocuidado para os pacientes do sexo feminino, com diferença significativa $(p<0,009)$. 0 reconhecimento da presença de edema de membros inferiores, o monitoramento diário do peso corporal e a prática regular de atividade física apresentaram-se como as medidas de autocuidado com maior discordância entre os participantes investigados. Conclusão: evidenciou-se melhor relação entre as medidas de autocuidado e o sexo feminino.

Descritores: Insuficiência Cardíaca; Autocuidado; Enfermagem.

${ }^{1}$ Universidade Federal da Paraíba. João Pessoa, PB, Brazil. 


\section{Introduction}

Heart failure is a complex chronic, systemic disease, considered the final route of most heart diseases. It is a serious public health problem ${ }^{(1)}$. It is estimated that 26 million people in the world have heart failure. In Latin America, decompensated heart failure stands out as the main cause of hospitalization for cardiovascular disease, with the highest frequency in people 65 years of age or older ${ }^{(2)}$.

Although great advances have occurred in the clinical and therapeutic management of the disease, there is a great challenge for health teams involved in the care of the person with heart failure, the maintenance of clinical stability by the patients, in view of the changes necessary to be incorporated in the practice of activities of daily living, focusing on the preservation of functional capacity and quality of life ${ }^{(3)}$.

In this sense, self-care actions become essential to minimize advances in cardiac remodeling, as well to avoid acute decompensation that contributes to unfavorable clinical outcomes. Self-care consists in the practice of activities that individuals perform in their benefit for themselves in the maintenance of life, health and well-being ${ }^{(4)}$.

Among the self-care activities recommended for patients with heart failure are the recognition of signs and symptoms of clinical decompensation, restriction of sodium and liquid diet, daily monitoring of body weight and correct and regular use of medications ${ }^{(5)}$. These actions become essential and necessary to minimize indicators of morbidity and mortality and undesirable hospital readmissions, reflecting a decrease in health expenditures for treatment of the disease, as well as a better perception of quality of life and survival.

A systematic review study that aimed to evaluate the factors associated with self-care of patients with heart failure identified factors such as age, health-related quality of life, gender, schooling, functional class, depressive symptoms and left ventricular ejection fraction, most frequently correlated with self-care behavior. However, it is suggested that new research be conducted with the purpose of better understanding of these factors, since they presented inconsistency in the association ${ }^{(6)}$.

In view of this, it is evident the need to broaden the state of the art on the subject, to better clarify the contributory and non-contributory aspects to the adoption of self-care, incorporating it into the behavioral category of people with heart failure. It is added that the studies developed in the Brazilian scenario involving self-care behaviors of this population are concentrated in the South ${ }^{(7)}$ and Southeast ${ }^{(8-9)}$ regions, proving it necessary to propose new research in the different contexts of the country, once in the Northeast region, the theme is little explored.

It is also important to highlight that the therapeutic approach to people with heart failure is a complex task due to the progressive pathophysiological process of the disease. Nursing is the field of knowledge whose generated knowledge reverts to the care of people. Therefore, professionals need to conduct research in order to explore phenomena that may subsidize new care technologies aimed at health promotion, adhesion to therapeutics and quality of life.

In this sense, the present investigation has raised the following question: what is the relationship between self-care measures adopted by patients with heart failure and their social and clinical conditions? The aim of this study was to identify self-care measures and their relationship to the social and clinical conditions of patients with heart failure.

\section{Methods}

Cross-sectional study, carried out at the cardiology outpatient clinic of a teaching hospital in the city of João Pessoa, Paraíba, Brazil. The study population comprised patients with a diagnosis of heart failure.

The following inclusion criteria were considered: patients with medical diagnosis of heart failure, aged $\geq 18$ years, of both sexes, in an outpatient follow-up at the selected institution. Exclusion criteria were: 
patients presenting barriers to comprehension, communication and confirmed cognitive dysfunction in medical records.

In the period from April 2016 to March 2017, data collection was carried out, through non-probabilistic sampling and consecutively. During this period, 103 patients with heart failure were treated; of these, one refused to participate in the study and two were unable to participate due to barriers of understanding and communication. The final sample consisted of 100 patients. The data were collected in the waiting room of the outpatient clinic, in a reserved place, through an interview, by a nurse with experience in the care of patients with heart disease, who was trained to collect data.

For the collection of sociodemographic and clinical variables, an instrument used in a previous study ${ }^{(3)}$ was used with patients with heart failure, a product of the activities developed together with the Study Group and Research in Chronic Diseases, Universidade Federal da Paraíba, Brazil, which is composed of age, sex, schooling, marital and occupational status, family income, etiology of heart failure, functional class according to the New York Heart Association (NYHA) criteria. In addition, a left ventricular ejection fraction was recorded, as recorded in an echocardiogram report, personal history (comorbidities) and pharmacological treatment.

Self-care evaluation was obtained through the European Heart Failure Self-care Behavior Scale (EHFScBS), a validated version for Brazilian Portuguese $^{(10)}$. The EHFScBS consists of 12 questions with a single domain related to self-care behavior, consisting of items such as daily body weight verification (item 1), rest (items 2 and 7), seeking help through health team (items 3, 4, 5 and 8), restriction of liquids (item 6), diet with low salt content (item 9), adhesion to medications (item 10), annual influenza vaccination (item 11) and regular practice of exercises (item 12). The answers for each item range from 1 , "I fully agree," to 5, "I strongly disagree," following a five-point Likert scale. The total score is obtained by the sum of all the answers, which can vary from 12 to 60 points. The low values indicate better self-care, however, there is no defined cut-off point ${ }^{(10)}$.

The data was transported to a spreadsheet using the Microsoft Office Excel Program containing a dictionary (codebook). They were then compiled and processed with the help of the Statistical Package for the Social Science, version 21.0, and subjected to descriptive and inferential statistical analysis.

Continuous variables were expressed as average and standard deviation, and categorical variables were expressed by absolute and relative frequencies. Data normality was demonstrated using the Kolmogorov-Smirnov test. The relationship between the averages of the self-care score and the variables with only two categories was tested using Student's t-test. For the variables with three or more categories, the ANOVA one way test was applied. The level of significance was set at 0.05 .

The study complied with the formal requirements contained in national and international standards for research involving human beings. The research project was approved by the Research Ethics Committee of the University Hospital Lauro Wanderely, according to opinion no $1,255,863$ and CAEE No.: 49420015.9.0000.5183.

\section{Results}

The study included 100 patients with heart failure, average age $58.99 \pm 14.00$, ranging from 19 to 87 years. Regarding the provenance of the sample, $61.0 \%$ belonged to the municipality of João Pessoa and 39.0\% lived in other municipalities. $61.0 \%$ were male, $62.0 \%$ were self-declared non-whites, $61.0 \%$ were married or in a stable union, $58.0 \%$ had schooling $\leq 9$ years of schooling, $77.0 \%$ were economically inactive, $60.0 \%$ had family income of one minimum wage.

Regarding the clinical characteristics, it was verified that the majority were in functional classes I and II (48.0\% and 45.0\%, respectively), according to NYHA criteria; $83.0 \%$ of the interviewees did not 
smoke, $90.0 \%$ did not practice regular physical activity and $86.0 \%$ did not perform nutritional monitoring. Regarding the presence of comorbidities associated with heart failure, $41.2 \%$ had systemic arterial hypertension and $19.9 \%$ had diabetes mellitus. Regarding the etiology of heart failure, $42 \%$ had myocardiopathy of ischemic origin. The average left ventricular ejection fraction was $46.89 \pm 16.02$, ranging from $19.0 \%$ to $78.0 \%$. The main medications used by the participants were diuretics, with $30 \%$, and beta-blockers, $25.7 \%$.

In the evaluation of self-care, the score obtained presented an average of $35.17 \pm 7.87$, with a variation of 15 to 54 points. Self-care measures that involved the recognition of clinical signs of cardiac decompensation, such as daily monitoring of body weight, contact with the health team due to the presence of lower limb edema, and regular practice of physical activity showed greater disagreements among participants.

Table 1 shows the relationship of social conditions with the self-care measures of the investigated participants. Regarding the self-care measure, it was found a lower average in the female sex, showing a better self-care in this group, with a statistically significant difference.

Table 1 - Relationship between self-care and social conditions of patients with heart failure

\begin{tabular}{|c|c|c|c|}
\hline Social variables & $\mathbf{n}$ & $\begin{array}{l}\text { Average of self-care } \\
\pm \text { standard deviation }\end{array}$ & $\mathbf{p}$ \\
\hline \multicolumn{4}{|l|}{ Age (years) } \\
\hline$\leq 60$ & 49 & $34.41 \pm 8.15$ & \multirow{2}{*}{0.362} \\
\hline$>60$ & 51 & $35.90 \pm 7.60$ & \\
\hline \multicolumn{4}{|l|}{ Gender } \\
\hline Male & 61 & $36.80 \pm 7.27$ & \multirow{2}{*}{$0.009^{*}$} \\
\hline Female & 39 & $32.62 \pm 8.19$ & \\
\hline \multicolumn{4}{|l|}{ Race } \\
\hline White & 38 & $35.11 \pm 8.30$ & \multirow{2}{*}{0.950} \\
\hline Non white & 62 & $35.21 \pm 7.67$ & \\
\hline \multicolumn{4}{|l|}{ Marital status } \\
\hline Single & 17 & $33.65 \pm 7.15$ & \multirow{4}{*}{0.391} \\
\hline Married/stable union & 61 & $36.07 \pm 8.19$ & \\
\hline Divorce/Separated & 11 & $32.18 \pm 6.36$ & \\
\hline Widow(er) & 11 & $35.55 \pm 8.34$ & \\
\hline \multicolumn{4}{|l|}{ Schooling (years) } \\
\hline No schooling & 33 & $36.52 \pm 7.66$ & \multirow{3}{*}{0.429} \\
\hline$\leq 9$ & 58 & $34.71 \pm 7.38$ & \\
\hline$>9$ & 9 & $33.22 \pm 11.42$ & \\
\hline \multicolumn{4}{|l|}{ Professional status } \\
\hline Active & 23 & $34.74 \pm 9.81$ & \multirow{2}{*}{0.767} \\
\hline Inactive & 77 & $35.80 \pm 7.26$ & \\
\hline \multicolumn{4}{|c|}{ Family income (minimum wage) } \\
\hline$<1$ & 1 & 31.00 & \multirow{3}{*}{0.753} \\
\hline 1 & 60 & $34.87 \pm 7.90$ & \\
\hline$>1$ & 39 & $35.74 \pm 7.98$ & \\
\hline
\end{tabular}

Table 2 shows the relationship of the clinical conditions with the self-care measures of the participants. It was observed that patients with functional class III and with more than one comorbidity associated with heart failure had higher scores, showing a worse behavior for self-care, although there was no significant association between the variables analyzed.

Table 2 - Relationship between self-care and clinical conditions in patients with heart failure

\begin{tabular}{lccc}
\hline Clinical variables & n $\begin{array}{c}\text { Average self-care } \pm \\
\text { standard deviation }\end{array}$ & p \\
\hline Etiology & 38 & $34.53 \pm 6.70$ & 0.525 \\
$\quad$ Ischemic & 62 & $35.56 \pm 8.54$ & \\
$\quad$ Non ischemic & & & \\
Functional Class New York Heart & & & \\
Association & 48 & $34.65 \pm 7.38$ & 0.524 \\
I & 45 & $35.24 \pm 7.12$ & \\
II & 7 & $38.29 \pm 14.50$ & \\
III & & & \\
Comorbidity & 18 & $32.12 \pm 10.50$ & 0.079 \\
1 & 82 & $35.80 \pm 7.14$ & \\
$>1$ & & &
\end{tabular}

\section{Discussion}

As a limitation of this study, it is possible to point out the self-referenced self-care measure, in addition to the cross-sectional design, which makes it impossible to assess behavior over time and inference of causality relationships. It is suggested that further research be conducted in order to corroborate or refute the evidence raised in this investigation. In addition, the sample size may not have been sufficient to generalize the results found, since, statistically, no significant relationships were found between the clinical conditions analyzed and the score of the self-care scale.

For nursing practice, the findings allow new perspectives of future studies, directing subjects that need to be clarified in the education of patients with heart failure. Nursing interventions, such as nursing consultations, home visits and remote monitoring, should be implemented in order to enhance self-care 
and, therefore, favor the maintenance of the clinical stability of this population.

Concerning social conditions, it is possible to observe lower self-care scores for female patients, in which a statistically significant relation was found $(\mathrm{p}<0.009)$. In the literature, there is not enough evidence to differentiate self-care and sex in heart failure $^{(3)}$. This data refers to reflections that the female population studied may have a better ability to cope with the disease, greater knowledge and adhesion to the therapeutic measures proposed for heart failure.

This result corroborates a survey conducted in southeastern Brazil ${ }^{(8)}$, but diverges from a study conducted in the northeast of the country ${ }^{(11)}$, whose male scores were better for maintaining self-care capacity. Thus, further investigations with a longitudinal approach should be conducted in order to produce consistent scientific evidence that differentiates self-care behavior between the sexes.

Regarding marital status, it was found higher scores for patients living married/stable union versus divorced. The data found disagree with the literature, since the evidence shows that married patients have better family support and motivation to cope with the changes necessary for the therapeutic management of heart failure compared to those who live alone ${ }^{(12-13)}$.

According to this assertion, a study carried out in Colombia concluded that family care for patients with heart failure contributes to better adaptation to new lifestyle demands, since it collaborates in a positive way to maintain and supervise appropriate selfcare actions, minimizing crises of clinical decompensation $^{(12) \text {. }}$

A clinical trial conducted in Iran, which aimed to assess family support in self-care behaviors in patients with heart failure, has shown that after educational interventions conducted through educational sessions and telephone monitoring, self-care has improved, given the support and motivation of to carry out the necessary measures for clinical stability of the disease, such as following a low sodium diet and a net restriction ${ }^{(14)}$.
Thus, family participation and social support networks become essential as support in the health/ disease process of patients with heart failure. It is suggested that nursing interventions be developed with the scope of enhancing family care for better management of self-care.

With regard to schooling, it was found that the participants with lower educational levels presented higher scores, revealing impaired self-care measures. This data is in addition to similar research developed in the national context ${ }^{(8-9)}$ where the level of schooling stands out as a social factor of extreme relevance for adhesion to measures aimed at pharmacological and non-pharmacological management of heart failure.

In this sense, a study conducted in the southern region of Brazil found a significant correlation between self-care and schooling, showing that the longer the study, the better management for self-care ( $r s=-0.278 ; p=0.012)^{(7)}$. Based on the results obtained, although the self-care versus education relationship was not significant, among the school categories defined in the present study, the lower the self-care score, the higher the level of schooling, which is consistent with the results of the research cited previously.

Thus, it is considered that patients with higher level of education have better conditions of access to health services, as well as understanding and knowledge about the disease, besides the therapeutic management necessary for the recognition of clinical signs of decompensation and decision making.

Regarding clinical characteristics, patients with NYHA functional class III and those with more than one comorbidity associated with heart failure had higher scores, therefore, greater difficulties in performing self-care actions. In view of these characteristics, the findings are consistent with the literature, which shows that patients with greater cardiac involvement are more susceptible to noncompliance with self-care recommendations and, therefore, hospital admissions due to clinical decompensation events ${ }^{(8,15)}$.

Therefore, with regard to the self-care measure assessed through the EHFScBS, the results indicated 
impaired self-care among study participants. Although the scale did not indicate a midpoint to classify the self-care behavior in preserved or impaired, it was found that the average score obtained $(35.17 \pm 7.87)$ for the total score (60 points) showed a tendency to higher values, evidencing that the evaluated patients obtained impaired self-care.

In the evaluation of the issues that make up the EHFScBS, it was observed that patients presented higher frequencies of disagreement in the questions regarding daily monitoring of body weight (Q1), recognition of lower limb edema (Q4) and physical activity practice (Q12).

A survey conducted in 15 countries $^{(4)}$, with a total of 5,964 participants, identified that less than half of the respondents were monitoring body weight and more than $50.0 \%$ reported low adhesion to physical activity, data that partially corroborate our findings, since the inactivity index reached $90 \%$, which is aggravating for the group studied.

For this variable, it was verified the greater frequency of disagreement between the questions of the instrument, revealing the difficulty of this population to adhere to the physical activity. It is understood that the disagreement to perform physical activities may be related to the fear of exacerbating symptoms of fatigue, dyspnea and physical limitations caused by heart failure.

The literature emphasizes that the practice of physical exercise should be individualized and compatible with the functional class of the patient. Aerobic exercises and light walking should be encouraged. In addition, the physiological and emotional benefits derived from this practice favor better coping and decrease in levels of anxiety and stress linked to the disease ${ }^{(9)}$.

In this sense, it is necessary, through public health management, to incorporate cardiac rehabilitation networks, linked to primary care, in order to practice physical activity as a measure of self-care, contributing to the maintenance of functional capacity, quality of life and active aging of this population.

In the present investigation, signs of clinical decompensation, such as the presence of lower limb edema and sudden gain of body weight, were impaired. The early recognition of these signs provides insights into the perception of clinical manifestations of hypervolemia. In addition, daily monitoring of weight helps to adjust diuretic dose; favoring adhesion to drug therapy, contributing to minimize further hospital readmissions and maintenance of functional capacity $^{(4-5)}$.

It is presumed that the investigated patients do not perceive the importance of these actions, which could justify the averages obtained. These results are in line with a study carried out in Italy, which revealed inadequate self-care for the recognition of signs of decompensation ${ }^{(15)}$. Thus, it is incumbent upon health professionals involved in the care of patients with heart failure to fill gaps in knowledge about the disease and to intensify the importance of non-pharmacological actions of self-care in the context of daily life, with the aim of minimizing life-threatening complications.

\section{Conclusion}

The results showed lower self-care scores for the female participants, showing a better relation in this group, whose findings were statistically significant. Among the self-care measures, there was greater disagreement in the daily monitoring of body weight, in the recognition of lower limb edema and in the practice of physical activity.

\section{Collaborations}

Sousa MM contributed in the design, in the data collection, in the writing of the article and interpretation of the data. Carvalho MF assisted in the data collection and writing of the article. Almeida TFC, Gouveia BLA and Brito FM contributed in the interpretation of the data and writing of the article. Oliveira SHS participated in the analysis and interpretation of data, critical review of the intellectual content and final approval of the version to be published. 


\section{References}

1. Oliveira SKP, Lima FET. Content validation of the self-careassessmentscale for heartfailurepatients. Rev Rene. 2017; 18(2):148-55. doi: http://dx.doi. org/10.15253/2175-6783.2017000200002

2. Boisvert S, Belhumeur AP, Gonçalves N, Doré M, Francoeur J, Gallani MC. An integrative literature reviews on nursing interventions aimed at increasing self-care among heart failure patients. Rev Latino-Am Enfermagem. 2015; 23(4):753-68. doi: dx.doi.org/10.1590/0104-1169.0370.2612

3. Sousa MM, Oliveira JS, Soares MJGO, Bezerra SMMS, Araújo AA, Oliveira SHS. Association of social and clinical conditions to the quality of life of patients with heart failure. Rev Gaúcha Enferm. 2017; 38(2):e65885. doi: http://dx.doi. org/10.1590/1983-1447.2017.02.65885

4. Jaarsma T, Stromberg A, Gal TB, Cameron J, Driscoll A, Duengen HD, et al. Comparison of self-care behaviors of heart failure patients in 15 countries worldwide. Patient Educ Couns. 2013; 92(1):114-20. doi: http://dx.doi.org/10.1016/j. pec.2013.02.017

5. White MF, Kirschner J, Hamilton MA. Self-care guide for the heart failure patient. Circulation. 2014; 129(3):e293-4. doi: http://dx.doi.org/10.1161/ CIRCULATIONAHA.113.003991

6. Sedlar N, Lainscak M, Martensson J, Strömberg A, Jaarsma T, Farkas J. Factors related to selfcare behaviours in heart failure: a systematic review of European Heart Failure SelfCare Behaviour Scale studies. Eur J Cardiovasc Nurs. 2017; 16(4):272-82. doi: http://dx.doi. org/10.1177/1474515117691644

7. Linn AC, Azollin K, Souza EM. Association between selfcare and hospital readmissions of patients with heart Failure. Rev Bras Enferm. 2016; 69(3):500-6. doi: dx.doi.org/10.1590/00347167.2016690312i
8. Conceição AP, Santos MA, Santos B, Cruz DALM. Self-care in heart failure patients. Rev Latino-Am Enfermagem. 2015; 23(4):578-86. doi: http:// dx.doi.org/10.1590/0104-1169.0288.2591

9. Ferreira VMP, Silva LN, Furuya RK, Schmidt A, Rossi LA, Dantas RAS. Self-care, sense of coherence and depression in patients hospitalized for decompensated heart failure. Rev Esc Enferm USP. 2015; 49(3):388-94. doi: http://dx.doi. org/10.1590/S0080-623420150000300005

10. Feijó MK, Ávila CW, Souza EM Jaarsma T, Rabelo ER. Cross-cultural adaptation and validation of the European Heart Failure Self-care Behavior Scale for Brazilian Portuguese. Rev Latino-Am Enfermagem. 2012; 20(5):988-96. doi: http:// dx.doi.org/10.1590/S0104-11692012000500022

11. Medeiros J, Medeiros CA. Assessment of self-care in heart failure patients. Cogitare Enferm. 2017; 22(3):e51082. doi: http://dx.doi.org/10.5380/ ce.v22i3.51082

12. Saldaña DMA, Sánchez AR, Castro NMT, Mora ALB, Beltrán NXN, Florez PD. Skills of family caretakers to care for patients with heart failure. Rev Cuid. 2017; 8(3):1721-32. doi: http://dx.doi. org/10.15649/cuidarte.v8i3.407

13. Srisuk N, Cameron J, Ski CF, Thompson DR. Randomized controlled trial of family-based education for patients with heart failure and their carers. J Adv Nurs. 2017; 73(4):857-70. doi: http://dx.doi.org/10.1111/jan.13192

14. Shahriari M, Ahmadi M, Babaee S, Mehrabi T, Sadeghi M. Effects of a family support program on self-care behaviors in patients with congestive heart failure. Iran J Nurs Midwifery Res [Internet]. 2013 [cited 2018 June 18]; 18(2):1527. Available from: https://www.ncbi.nlm.nih.gov/ pmc/articles/PMC3748572/

15. Cocchieri A, Riegel B, D’Agostino F, Rocco G, Fida R, Alvaro R, et al. Describing self-care in Italian adults with heart failure and identifying determinants of poor self-care. Eur J Cardiovasc Nurs. 2015; 14(2):126-36. doi: http://dx.doi. org/10.1177/1474515113518443 